\title{
Nükleer Santrallerde Yangın Güvenliği Açısından Reaktör Soğutmanın Önemi ve Fukuşima Daiichi Kazası Modeli Üzerinden Kontrol Dışı Gerçekleșen Fisyon Reaksiyonlarının Enerjisinin Hesaplanması
}

\author{
Yılmaz UYAROĞLU ${ }^{1}$ ve Şenol AY²
}

\section{Özet}

$\mathrm{Bu}$ makalede nükleer enerji santrallerinde patlamanın oluşmasına neden olan durumlar değerlendirilerek, kontrol dıșı gerçekleșen fisyon reaksiyonları sonucu açığa çıkan enerjinin hangi durumlara neden olabileceği araștırılmıștır. Model olarak ele alınan Fukuşima Daiichi Nükleer santralinde soğutma sistemi doğal afet nedeni ile devre dışı kalan üç ünitedeki reaktörlerde, üç gün içinde devam eden fisyon reaksiyonları sonucu açığa çıkan enerjinin hesaplanması için W.s'lik enerji elde etmek için gereken fisyonların sayısı bulunmuş, daha sonra bu enerjinin oluşabilmesi için kullanılması gereken U-235 kütlesi hesaplanarak toplamda üç reaktör için $2028 \mathrm{MW} / \mathrm{h}$ enerji üretimi miktarı baz alınarak harcanan U-235 kütlesi hesaplanmış ve 67 saat süre sonunda ortamda kontrolsüz olarak oluşacak enerji, sonuçlarının değerlendirilebilmesi için hesaplanmıştır. Hesaplamalara göre 3,4273 kg U-235 harcanması sonucu $2028 \mathrm{MW} / \mathrm{h}$ enerji açığa çıkmıştır. Bu enerjinin santralde yaşanan patlama olayına hangi şartlarda neden olduğu açıklanmıştır.

Anahtar Kelimeler: Nükleer Güç Santralleri, Yangın, Patlama, Nükleer Enerji

\section{The Importance of Reactor Cooling For Fire Safety in Nuclear Power Plants And Calculation of The Energy of Uncontrolled Fixation Reactions Via Fukushima Daiichi Accident Model}

\begin{abstract}
1Profesör, Eleketrik Elektronik Mühendisliği Bölümü, Sakarya Üniversitesi, Sakarya

İlgili yazar / Corresponding author: uyaroglu@sakarya.edu.tr

2Yangın Ve Yangın Güvenliği Bilim Uzmanı, Fen Bilimleri Enstitüsü , Sakarya Üniversitesi, Sakarya

İlgili yazar / Corresponding author: senol.ay1@ogr.sakarya.edu.tr
\end{abstract}

The residual heat and fission reactions caused by the failure of safety systems and backup generators after natural disaster in Fukushima Daiichi accident caused an explosion in the power plant. In this article, the energy that causes the explosion is calculated and the possible negative effects of this energy is explained. The number of fusions required to obtain W energy has been found to be able to calculate the energy released by fission reactions within three days in the reactors in the three units that have been disabled due to natural disaster at the cooling system of the Fukushima Daiichi nuclear power plant. Then, the mass of U-235, which is calculated based on the amount of energy production of $2020 \mathrm{MW} / \mathrm{h}$ for three reactors, was calculated by calculating the mass of U-235 which should be used to form this energy, and after 67 hours, uncontrolled energy in the environment was calculated to evaluate the results. According to the 
Nükleer Santrallerde Yangın Güvenliği Açısından Reaktör Soğutmanın Önemi ve Fukuşima Daiichi Kazası Modeli Üzerinden Kontrol Dıșı Gerçekleșen Fisyon Reaksiyonlarının Enerjisinin Hesaplanması calculations, an energy consumption of 3,4273 kg U-235 resulted in $2028 \mathrm{MW} / \mathrm{h}$ energy and in joule it was found to be $2028000 \mathrm{Kj} / \mathrm{h}$. It was explained how this energy caused the explosion in the plant.

This research; it is aimed to contribute to the future studies and to take measures against the situations that cause the explosion in nuclear power plants.

Keywords: Nuclear Power Plants, Fire, Explosion, Nuclear Energy

\section{GíRiş}

Ülkemizde ve dünyada çoğalan nüfus ile birlikte enerji ihtiyacı sürekli artmakta ve tüm dünyada olduğu gibi ülkemizde de, artan enerji ihtiyacını karşılamak amacıyla farklı çözüm yolları arayışı içine girilmektedir. Türkiye'de nükleer santraller kurulmasıyla ilgili ilk somut gelişme 15 Ekim 1997 tarihinde AECL, Nuclear Power International (Siemens ve Fransiz Framatorme konsorsiyumu) ve ABD Westinghoues-Japon Mitsubishi konsorsiyumu Türkiye'ye teklifler sunmasıyla gerçeklești ve teklifler TEAŞ (Türkiye Elektrik Üretim İletim A.Ş.) Nükleer Santraller Dairesi ve danışman şirket Empresarios Agrupados International S:A tarafından incelendi, önerilen santrallerin tümünün eski teknoloji olduğu ve nükleer enerjide yeni gelişmeler olacağı gerekçesiyle süreç olumsuz sonuçlandı.

Nitekim yeni gelişmelerde oldu ve açılan yeni ihale Rus Devlet Nükleer Şirketi'ne bağlı bulunan NGS AŞ'ye verildi. Rusya ve Türkiye arasındaki nükleer santral yapımını öngören hükümetler arası anlaşma 2011 yılında açıklandı. Yapılan açılamada; Akkuyu'da yapılması planlanan nükleer santralin Rus tedarikçi şirketi Rusatom Overseas'in Başkan Yardımcısı Jukka Laaksonen: Akkuyu'da santral inşaatına 2015 yılı sonunda başlanması planlanıyor, Mersin (Akkuyu) ve Sinop'da (İnceburun) 2023 yılında iki nükleer santralin de faal olacağını söyledi. Bu arada Sinop'ta yapılacak nükleer santral ise Japon Mitsubishi ve Fransız Areva ortaklığı tarafından inşa edilmesi kararlaştırıldı. (Özbay ve Gençoğlu, 2011)

\subsection{Nükleer Santrallerde Güvenlik Ve Önleme Sistemleri}

Nükleer santrallerde güvenlik sistemleri yapılandırılırken yangın başta olmak üzere dış kaynaklı afetlerin ve olayların yanı sıra iç kaynaklı arıza ve kazalar da göz önünde bulundurularak en olumsuz durumda dahi santralin, yapıların ve sistem unsurlarının güvenliğinin sağlanması ve insanların ve doğanın zarar görmemesinin sağlanması amaçlanmaktadır. İnsanların ve doğanın radyolojik zararlardan korunması NGS'lerdeki güvenlik ve önleme sistemlerinin en temel amacını oluşturmaktadır. $\mathrm{Bu}$ bağlamda NGS'lerdeki güvenlik ve önleme sistemlerinin gerekliliklerini şu şekilde sıralamak mümkündür:

1. Kazaların ve istenmeyen olayların meydana gelmesini önlemek,

2. Alınan bütün önlemlere rağmen kaza meydana gelmesi durumunda kazanın sonuçlarının en az seviyeye indirilmesini sağlamak,

3. Meydana gelme ihtimali en az olan kazalar da dahil olacak şekilde, tesisin dizaynında göz önünde bulundurulan tüm kazalar ve istenmeyen olaylar için, radyolojik sonuçların etkilerinin belirlenen sınırların üstüne çıkmasını engellemek,

4. Ağır radyolojik etkileri olabilecek büyük boyutlardaki kazaların meydana gelmesi ihtimalinin makul düzeyde düşük olmasını sağlayacak her türlü önlemin alınmasını sağlamak. (URL 1)

\subsection{Dünyada Yaşanan Nükleer Kaza Ve Olaylar}

Nükleer tesislerdeki enerji üretim sürecinde reaksiyonların ve süreç sonundaki atıkların kontrol dışına çıkarak insanlara ve doğaya zarar vermesi nükleer kaza olarak tanımlanmaktadır (URL 2). 
Afet ve Risk Dergisi Cilt: 2 Sayı: 2, 2019 (95-104)

Yılmaz UYAROĞLU, Şenol AY

Fukuşima'da meydana gelen nükleer kaza örneğinde de görüldüğü gibi doğal afetler nükleer kazaların meydana gelmesinde önemli bir faktör sayılmaktadır. Bu bağlamda doğal afetleri, nükleer kazalardan ve felaketlerden ayrı düşünmemek gerekmektedir.

Nükleer kazaların büyüklüğü Uluslararası Atom Enerji Ajansı ve OECD tarafından geliştirilen ve 1989 yılından itibaren aktif olarak kullanılan 'Uluslararası Nükleer ve Radyolojik Olay Ölçeği Sistemi (INES) ile belirlenmektedir (Şekil 1, URL 3). Bu ölçek bağlamında, nükleer kazalar ve olaylar büyüklüklerine göre yedi basamakta ele alınmaktadır. Buna göre bir ile üçüncü basamaklar arasında küçük nükleer olaylar, dört ile yedinci basamaklar arasında ise nükleer kazalar tanımlanmaktadır (URL 2). Uluslararası Atom Enerjisi Ajansı tarafından hazırlanan rapora göre, 1987 ile 2013 yılları arasında INES ölçeğine göre çeşitli büyüklüklerde 611 olay ve kaza raporlanmıștır. INES ölçeği seviyelerine göre meydana gelen olayların 6'sı dört ve üstü seviyede ve nükleer kaza olarak sinıflandırılırken, 41'i üçüncü seviye ciddi olay olarak sınıflandırılmıştır (Güler, 2006).

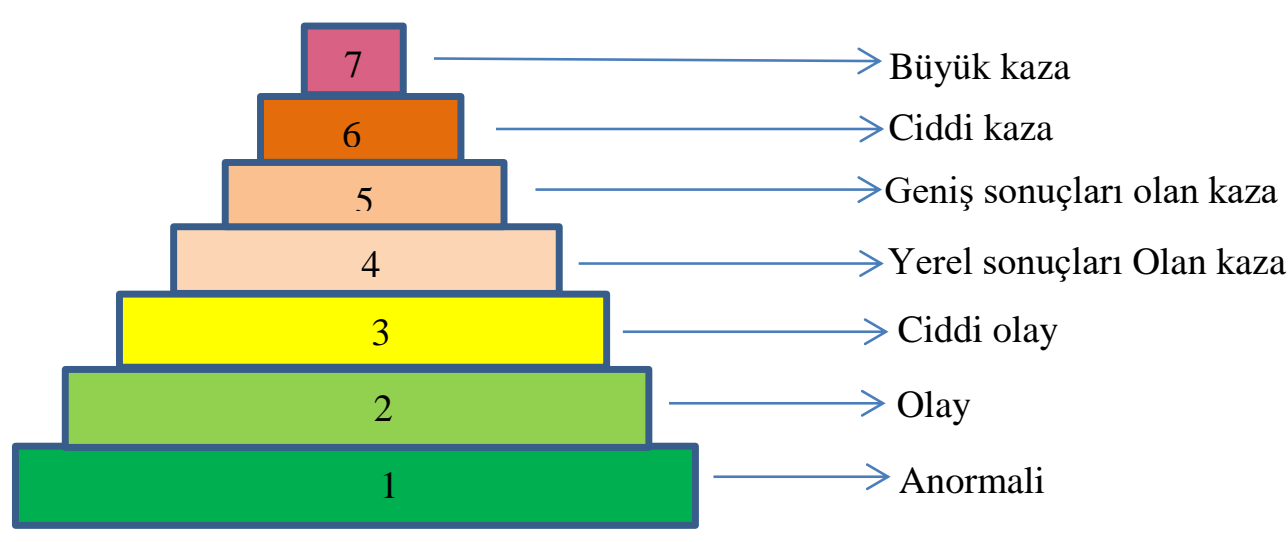

Şekil 1. INES Ölçeğine göre nükleer olayların basamaklandırılması (Gunter, 2004)

Uluslararası Atom Enerjisi Ajansı'nın verilerine göre dünyada gerçekleșen nükleer sızıntı ve seviyeleri aşağıda Şekil 2'de görülmektedir. Şekil 2 incelendiğinde bazı ülkelerde kaza sayısının fazla olduğu fakat kaza etkilerinin düşük olduğu görülmektedir. Japonya dışındaki gelişmiş ülkelerde INES ölçeği 4 üzerinde olan nükleer sızıntıya sebep olabilecek kaza veya olayın yaşanmadığı görülmektedir. Dünya tarihinde yaşanan en büyük nükleer sızıntı kazalarının ise yangın ve patlama sonrası meydana geldiği görülmektedir. Yangın ve patlamaya neden olan durumlar her ne kadar farklı olsa da sonuçlar ve etkiler benzer şekilde olmaktadır.

\section{FUKUŞIMA NGS KAZASI VERİLERİNİN DEĞERLENDİRİLMESİ}

Çalışmanın bu bölümünde nükleer güç reaktörlerinde meydana gelebilecek proses hataları veya doğal afet nedeni ile güvenlik sistemlerinin devre dışı kalması nedeniyle yangın ve patlama olaylarının gerçekleşmesi, Fukuşima Daiichi kazası model alınarak incelenecektir. Hesaplama için gerekli verilere Fukuşima Daiichi Kazası teknik raporundan ulaşılarak patlama olayının kök nedeni fizikokimyasal olarak açlklanacaktır. Nükleer santrallerde yer alan aktif ve pasif güvenlik ve önleme sistemlerinin bu kazayı engelleyememesi bu konuda yeterli çalışma yapılmadığı ve güvenlik önlemlerinde eksik olduğu gerçeğini göstermiştir (URL 5). 
Nükleer Santrallerde Yangın Güvenliği Açısından Reaktör Soğutmanın Önemi ve Fukuşima Daiichi Kazası Modeli Üzerinden Kontrol Dıșı Gerçekleșen Fisyon Reaksiyonlarının Enerjisinin Hesaplanması



Şekil 2. Nükleer sızıntı kaza ve olayların ülkelere göre İnes ölçeği bazında gösterimi (URL 4)

\subsection{Fukuşima Daiichi kazası'nın teknik rapor üzerinden incelenmesi}

Çalıșmanın bu bölümünde yaşanan kaza detaylı olarak incelenecek ve kazaya sebebiyet veren etkenlerin nicel parametreleri ortaya konacaktır. 11 mart 2011 de Japonyanın kuzey doğu kıyı şeridinde Fukuşima Daiichi santralinde kaza meydana gelmiştir. Saat akşam 2 : 46 da 9 büyüklügünde bir deprem doğu kıyısının $180 \mathrm{~km}$ üstünü vurdu. Halı hazırda çalışır durumda olan santralin 1,2,3, birimlerinin otomatik olarak kapanmasıyla sonuçlanmıştır. Deprem tesis dışı güç kaybıyla sonuçlanan bir zarara neden oldu fakat acil durumlar için bulunan dizel jeneratör bu 3 BWR (boiling water reactor) için soğutma sistemlerinin çalışabilmesi için devreye girmiştir. Depremden yaklaşık bir saat sonra 14, 15 metre yüksekliğinde bir tsunami santral alanını sular altında bırakmıştır. (Yoshioka ve Lino) Sonuç olarak tsunami ve sel acil durum dizel motorlarını ve diğer gerekli elektriksel şalterlerini çalışamaz hale getirmiştir. Hem tesis dışı hem de tesis içinde yaşanan enerji kaybı sonrası santral bir karartma durumuna geçmiştir. Bu noktada, sadece ünite 3 teki güç kaynakları bağlı aletler ve kontrol sistemlerine güç sağlıyordu. Bu enerji pompalar gibi yüksek enerji gerektiren prosesler için yeterli değildi (Keski ve Mangs, 2002). Fukuşima santrali toplam 6 adet üniteden oluşmaktadır. Birinci, ikinci ve üçüncü üniteler 1971 ile 1975 yllları arasında devreye alınmıștır. Ünitelerdeki reaktör güç üretimi değişiklik göstermektedir. Birinci ünite güç üretimi $460 \mathrm{MWe}$, ikinci üniteden altıncl üniteye kadar 784 MWe ve altıncı ünite için 1100 MWe'dir (Keski ve Mangs, 2002).

Riechter ölçeğinde 8.9 büyüklüğündeki depremin ardından gelen tsunami ile Fukuşima Nükleer Santralinde bulunan hafif su kaynar su tipi reaktörlerden üçüne güç sağlayan sistemler devre dışı kalmıștır. Santralde altı adet nükleer reaktör bulunmaktadır. 1,2 ve 3. reaktörler otomatik olarak kapanmıştır. Deprem sırasında 4. ünitede yakıt bulunmamaktadır ve 5. ve 6. üniteler rutin bakım sebebiyle soğuk kapama durumundadır (Keski ve Mangs, 2002).

$\mathrm{Bu}$ durum göz önüne alındığında patlamaya neden olanenerjinin 1,2,3 numaralı reaktörlerde kullanılan nükleer yakıt olduğu kabul edilerek hesaplamalar buna göre yapılacaktır. 


\section{TEKNIK RAPORDAN ELDE EDİLEN VERÍLERE GÖRE HESAPLAMALARIN YAPILMASI}

\subsection{Fukuşima Daiichi Kazasına Neden Olan Kontrolsüz Enerjinin Hesaplanması}

NGS'lerde geçmişte meydana gelen kaza ve olaylardan edinilen işletim tecrübeleri ve yangın güvenliği değerlendirmeleri yangın ve patlamaların NGS güvenliği üzerinde büyük bir öneme sahip olduğunu ortaya koymuştur. Bir NGS'de kaza yaşanma ihtimali her zaman devam ettiğinden, tasarım aşamasından işletilmesine ve işletmeden çıkarılmasına kadar geçen işletme ömrü boyunca NGS'lerin güvenli olarak işletilmesi ulusal ve uluslar arası toplumlar için oldukça önemlidir.

Model olarak ele alınan Fukuşima Daiichi nükleer santralinde kazaya neden olan enerjinin ve kazaya neden olan durumların kök neden analizi sonucu nicel veriler ortaya konulması, yeni kurulacak NGS'lerde benzer kazaların yaşanmasının önlemesi açısından çok büyük öneme sahiptir.

\subsection{Kaza Sonrası Kontrol Edilemeyen Enerjinin Hesaplanması}

W.s'lik enerji elde etmek için gereken fisyonların sayısı; aşağıda belirtilen formül (1) (Vinod vd., 2008) ile hesaplanır.

$$
\frac{1}{w}=\left(\frac{1 \text { fisyon }}{190 M e V}\right)\left(\frac{1 M e V}{1.602 \times 10^{-13} J}\right)=3.29 \times 10^{10} \frac{\text { fisyon }}{W . s}
$$

Her fisyon bir yakıt atomunun yanmasını gerektirir. Bir reaktörün bir günlük çalışmasında termal güç (MWt) başına, fisyon ile yanan U-235 çekirdeklerinin sayısı formül 2' deki gibi hesaplanır.

$$
\left(\frac{10^{6} W}{M W}\right)\left(\frac{3.29 \times 10^{10} \text { fisyon }}{W . s}\right)\left(\frac{86.400 s}{g}\right)=2.84 \times 10^{21} \frac{\text { atom }}{M W t . g}
$$

Bir günde 1 MW termal güç üretmek için tüketilen U-235 miktarı yukarıdaki verileri kullanarak hesaplandığında;

$$
\left(2.84 \times 10^{21} \frac{\text { bölünen-atomlar }}{\text { MWt.gün }}\right) \frac{\sigma_{a}}{\sigma_{f}}=\left(2.84 \times 10^{21}\right)\left(\frac{582.6+98.3}{582.6}\right)=3.32 \times 10^{21} \frac{\text { atomlar }}{\text { MWt.g }}
$$

olarak bulunur. Buradan açıkça görülmektedir ki, çeşitli yakıtlar kendi tesir kesitlerine bağlı olarak farklı miktarlarda üretilecektir. $235 \mathrm{~g}$. atomların avogadro sayısına denk geleceğinden harcanan U-235 kütlesi;

$$
\frac{\left(3.32 \times 10^{21} \text { atom } / \mathrm{MW} . \mathrm{g}\right)(235 \mathrm{~g} / \mathrm{mol})}{6.022 \times 10^{23} \mathrm{atom} / \mathrm{mol}}=1.30 \mathrm{~g} / \mathrm{MWt} . \mathrm{g}
$$

olarak bulunur. Gerçekte bölünen veya yanan U-235 kütlesi ise aşağıdaki gibidir. 
Nükleer Santrallerde Yangın Güvenliği Açısından Reaktör Soğutmanın Önemi ve Fukuşima Daiichi Kazası Modeli Üzerinden Kontrol Dıșı Gerçekleșen Fisyon Reaksiyonlarının Enerjisinin Hesaplanması

$$
\frac{\left(2.84 \times 10^{21} \mathrm{atom} / \mathrm{MW} . \mathrm{g}\right)(235 \mathrm{~g} / \mathrm{m})}{6.022 \times 10^{23} \mathrm{atom} / \mathrm{mol}}=1.11 \mathrm{~g} / \mathrm{MWt} . \mathrm{g}
$$

Riechter ölçeğinde 8.9 büyüklüğündeki depremin ardından gelen tsunami ile Fukuşima Nükleer Santralinde bulunan hafif su kaynar su tipi reaktörlerden üçüne güç sağlayan sistemler devre dışı kalmıştır. Santralde altı adet nükleer reaktör bulunmaktadır. 1,2 ve 3. reaktörler otomatik olarak kapanmıştır. Deprem sırasında 4. ünitede yakıt bulunmamaktadır ve 5. ve 6. üniteler rutin bakım sebebiyle soğuk kapama durumundadır (Yoshioka ve Lino).

$\mathrm{Bu}$ durum göz önüne alındığında 1,2,3 numaralı reaktörlerde oluşan enerji hesaplanması gerektiği sonucuna ulaşılır. Birinci ünitede $460 \mathrm{MWe}$, ikinci ve üçüncü ünitelerde ise $784 \mathrm{MWe}$ kapasite ile çalıştı̆̆ yukarıda belirtilmiştir. 2028 MWt üreten üç reaktörde U-235 tüketimi aşağıda belirtildiği gibi formül 3 ile hesaplanır;

$$
m c=(1.3 \mathrm{~g} / \mathrm{MWt} . \mathrm{g}) P_{t h}=(1.3 \mathrm{~g} / \mathrm{MWt} . \mathrm{d})(2028 \mathrm{MWt})=3,4273 \mathrm{~kg}
$$

3,4273 kg U-235 kullanılarak üretilen güç 2028 MW olarak bulunur.

Fukuşima genel elektrik santralinde yaşanan patlama olayı; soğutma ünitesine güç sağlayan jeneratörün su altında kalması dolayısı ile soğutma suyunun aşırı ısınması ile hidroliz olması ve açı̆̆a çıkan $\mathrm{H}_{2}$ gazının patlamaya neden olmasıdır. Bu durumun olabilirliğini değerlendirmek için suyun oluşum ile alakalı Gibbs serbest enerjisini belirlenmelidir. Aşağıdaki bağıntı (4) kullanılarak hesaplama yapılır.

$$
2 \mathrm{H}_{2}(\mathrm{~g})+\mathrm{O}_{2}(\mathrm{~g}) \longrightarrow 2 \mathrm{H}_{2} \mathrm{O}(\mathrm{s})
$$

Yukarıdaki tepkime ile alakalı termodinamik veriler aşağıdaki gibidir (Tablo 1).

Tablo 1. Suyun oluşumu ile alakalı termodinamik veriler (Cebe, 2014))

\begin{tabular}{|lccc|}
\hline & $\mathrm{O}_{2}(\mathrm{~g})$ & $\mathrm{H}_{2}(\mathrm{~g})$ & $\mathrm{H}_{2} \mathrm{O}(\mathrm{s})$ \\
$\Delta \mathrm{H}_{\mathrm{f}}{ }^{0}(\mathrm{kcal} / \mathrm{mol})$ & 0 & 0 & -285.83 \\
$\left.\mathrm{~S}^{0} \mathrm{~J} / \mathrm{mol}-\mathrm{K}\right)$ & 130.8 & 205.04 & 69.91 \\
$\Delta \mathrm{F}_{\mathrm{f}}{ }^{0}(\mathrm{kj} / \mathrm{mol})$ & 0 & 0 & -273 \\
\hline
\end{tabular}

$\mathrm{Bu}$ çizelgeden faydalanarak bir mol suyun oluşumunda ortaya çlkabilecek reaksiyon Gibbs serbest enerjisi $\left(\Delta \mathrm{F}_{\mathrm{r}}{ }^{0}\right)$ bulunabilir. Bulunan bu değer aynı zamanda suyun parçalanması için verilmesi gereken enerjidir. Tüm durum fonksiyonlarının kimyasal reaksiyona yönelik sayısal değerleri sırasıyla; çizelgeden yararlanarak ve mol sayıları gözetilerek ürünlerin standart olușum değerleri toplamıyla reaktanların benzer ișlemlerle belirlenen değerlerinin toplamlarının farkları şeklinde tanımlanabilmektedir. Tüm durum fonksiyonlarında (r) indisi; reaksiyonu karakterize etmekte kullanılmaktadır. Bu durumda seçilen reaksiyonla ilgili olarak reaksiyon entalpi değeri aşağıdaki formül e (5) göre hesaplanır.

$\Delta \mathrm{H}_{\mathrm{r}}^{0}=2(-285.83)-(2 \mathrm{x} 0+1 \mathrm{x} 0)=-571.66 \mathrm{kj}$

Benzer ş̧ekilde oluşum entalpilerini sırasıyla 4, 6, 8, 10, 12, 14, 16, 18, 20 mol su için bulunduğunda buradan bir grafik oluşturabilir ve buna göre soğutma ünitesindeki durum değerlendirilebilir. 
4 mol $\mathrm{H}_{2} \mathrm{O}$ molekülünün oluşum entalpisi hesaplanır ise;

$4 \mathrm{H}_{2}(\mathrm{~g})+2 \mathrm{O}_{2}(\mathrm{~g}) \longrightarrow 4 \mathrm{H}_{2} \mathrm{O}(\mathrm{s})$

$\Delta \mathrm{H}_{\mathrm{r}}{ }^{0}=4(-285.83)-(4 \mathrm{x} 0+2 \mathrm{x} 0)=-1143.32 \mathrm{kj}$ bulunur.

Tüm bu hesaplamaları 4, 6, 8, 10, 12, 14, 16, 18, 20 mol su için yapıldığında sırasıyla Tablo 2'de verilen değerlere ulaşılır.

Tablo 2. Suyun mol sayısına karşıllk oluşum entalpi değerleri

\begin{tabular}{|cccc|}
\hline $\mathrm{H}_{2} \mathrm{O}(\mathrm{mol})$ & $\Delta \mathrm{H}_{\mathrm{r}}{ }^{0}$ (reaksiyon entalpi değeri)(kj) & $\mathrm{H}_{2} \mathrm{O}(\mathrm{m})$ & $\Delta \mathrm{H}_{\mathrm{r}}{ }^{0}$ (reaksiyon entalpi değeri)(kj) \\
2 & -571.66 & 12 & -3429.96 \\
4 & -1143.32 & 14 & -4001.62 \\
6 & -1714.98 & 16 & -4573.28 \\
8 & -2286.64 & 18 & -5144.94 \\
10 & -2858.3 & 20 & -5716.6 \\
\hline
\end{tabular}

Bu değerler göz önüne alınarak mol sayısına karşllık oluşum entalpisi grafiği oluşturulduğunda bu sonuçlar nükleer santral soğutma suyunun atomlar arası bağların kırılarak $\mathrm{H}_{2}$ (g) oluşması için gerekli enerjinin Uranyumun bozunması ile oluşup oluşamayacağının değerlendirilebileceği verilere ulaşılmış olunur.

Suyun oluşum entalpi değerleri belirtilen reaksiyonun tam tersi ilerlediğinde, sudaki atomlar arası bağların kırılabilmesi için gerekli enerji olarak değerlendirilir. Bu kapsamda Fukuşima genel elektrik santralinde olayın yaşandığı reaktörde kullanılan Uranyum miktarını ve bozunma sonucu açığa çıkan enerjinin kaç mol $\mathrm{H}_{2} \mathrm{O}$ molekülünün hidroliz olayıyla parçalanabileceğini ve bu parçalanma sonucu açığa çıkan $\mathrm{H}_{2}$ gazının patlama limitlerine ulaşacağı hacim ile değerlendirerek meydana gelen patlama olayının nedenini Fizikokimyasal olarak doğrulanması amaçlanmaktadır. Bu değerler aşağıda tablo 3'te açıkça görülmektedir.

Tablo 3. $\mathrm{H}_{2} \mathrm{O}$ molekülü olușum entalpi değerleri

\begin{tabular}{|cccc|}
\hline $\mathrm{H}_{2} \mathrm{O}$ mol sayısı (mol) & $\begin{array}{c}\Delta \mathrm{H}_{\mathrm{r}}{ }^{0} \text { (reaksiyon entalpi } \\
\text { değeri)(kj) }\end{array}$ & $\mathrm{H}_{2} \mathrm{O}$ mol sayısı (mol) & $\begin{array}{c}\Delta \mathrm{H}_{\mathrm{r}}{ }^{0} \text { (reaksiyon entalpi } \\
\text { değeri) }(\mathrm{kj})\end{array}$ \\
1000 & 285830 & 6000 & 1715100 \\
2000 & 571660 & 7000 & 2000810 \\
3000 & 857490 & 8000 & 2286640 \\
4000 & 1143320 & 9000 & 2572470 \\
5000 & 1429150 & 10000 & 2858300 \\
\hline
\end{tabular}

$\mathrm{Bu}$ veriler dikkate alınarak $\mathrm{H}_{2} \mathrm{O}$ mol sayısına karşılık bağ kırılması için gereken enerji grafiği çizildiğinde hesaplanan kontrol dışı gerçekleșen reaksiyon sonucu oluşan enerji değerinrine karşılık gelen miktar hidrolize uğrayan suyun mol sayısı olacaktır.

Model olarak alınan 1. Ünitede yaklaşık olarak $6692 \mathrm{~mol} \mathrm{H}_{2} \mathrm{O}$ molekülünü hidroliz ederek, $\mathrm{H}_{2}$ gazı açı̆̆a çıkmasına neden olacağı aşağıdaki şekilde görülmektedir (Şekil 3 ). 
Nükleer Santrallerde Yangın Güvenliği Açısından Reaktör Soğutmanın Önemi ve Fukuşima Daiichi Kazası Modeli Üzerinden Kontrol Dıșı Gerçekleșen Fisyon Reaksiyonlarının Enerjisinin Hesaplanması

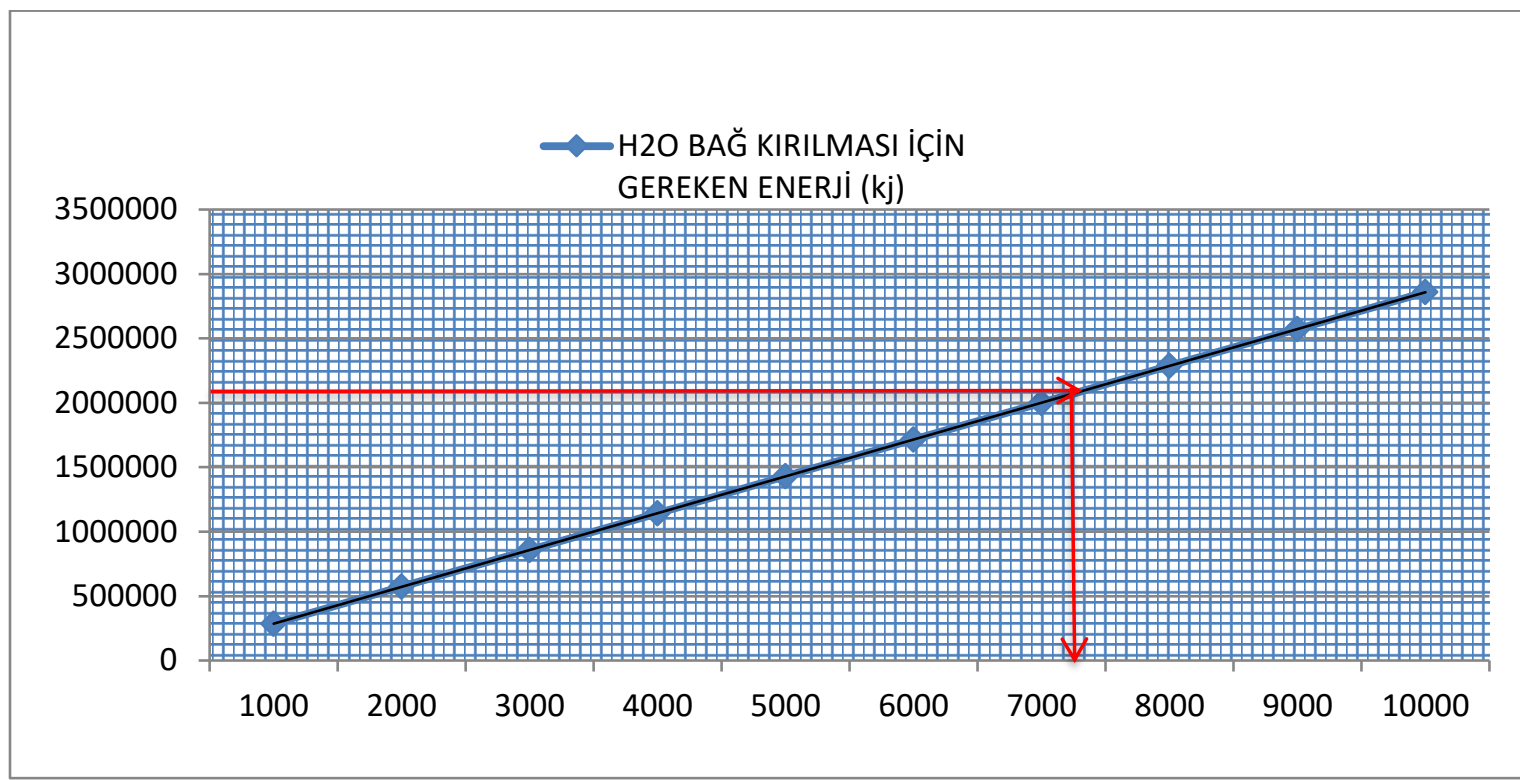

Şekil 3. Suyun mol sayısına karşılık bağ kırılması için gereken enerji (kj)

Reaksiyonuna göre $6692 \mathrm{~mol} \mathrm{H}_{2} \mathrm{O}$ molekülünün parçalanması sonucu açığa çıkacak $\mathrm{H}_{2}$ gazı yukarıdaki reaksiyona göre k $6692 \mathrm{~mol}$ olacaktır. Mol sayısı ile ifade edilen değer aşağıda formul 6. kullailarak gram olarak bulunur.

$n=\frac{m}{M_{A}}$

$\left(\mathrm{H}_{2}(\mathrm{~g}) \mathrm{MA}=2.016 \mathrm{~g} / \mathrm{mol}\right)$

Formüle göre $6692 \mathrm{~mol} \mathrm{H}_{2}$ (g) $13491 \mathrm{~g}$ olarak bulunur.

$\mathrm{Bu}$ verilere göre $13491 \mathrm{~g} \mathrm{H}_{2}$ gazının hangi hacimlerde patlayıcı ortam oluşturabileceği formül 7'de belirtildiği gibi hesaplanabilir. Bu değer 67 saat sonunda 11,8925 m³olur.

$d=\frac{m}{v}$

$76 \mathrm{~kg} / \mathrm{m}^{3}=\frac{13,491 \mathrm{~kg}}{v}=v=0.17756 \mathrm{~m}^{3}$

Teorik olarak hesaplanan değerler neticesinde oluşan $\mathrm{H}_{2}$ gazı 15,8566 $\mathrm{m}^{3}$ ile 297,31 hacimlerde patlayıcı ortam oluşturması beklenir. 


\section{SONUÇ, TARTIŞMA VE ÖNERİLER}

Dünya genelinde yaşanan Nükleer kaza ve olayları incelendiğinde bazılarının yangın veya patlama nedeniyle oluştuğu, bazılarının ise olay sonrasında yangın veya patlamaya neden olduğu görülmektedir. Çalışmada Fukuşima genel elektrik santralinde Hidrojen gazı patlamasını nedenleri incelenerek sürece giden yolun tahmin edilemeyen durumlarının neticesinde patlama olayının gerçekleşmesinin nedenleri fizikokimyasal hesaplamalar ile ortaya konulmuştur.

Sonuç olarak;

1) NGS'de gerçekleşen zincirleme reaksiyon sonucu açığa çıkan enerji kullanım amacı dışında $\mathrm{H}_{2} \mathrm{O}$ moleküllerinin hidrolizine sebep olarak patlamaya neden olan $\mathrm{H}_{2}$ gazının açığa çıkmasına sebep olmuştur. Bu değerler aşağıda Tablo 4'te görülmektedir.

Tablo 4. Patlamaya neden olan $\mathrm{H}_{2}$ gazı teorik hesaplama sonuçları

\begin{tabular}{ccccc}
\hline $\mathrm{H}_{2}(\mathrm{~g})$ & $\mathrm{H}_{2}(\mathrm{~kg})$ & $\mathrm{H}_{2}\left(\mathrm{~m}^{3}\right)$ & $\mathrm{H}_{2}$ (LEL) & $\mathrm{H}_{2}$ (UEL) \\
\hline $13491 / \mathrm{h}$ & 13,491 & 11,8925 & 4 & 75 \\
\hline
\end{tabular}

2) Ortamda biriken yanıcı ve patlayıcı gazı tahliye etmek için tasarlanan havalandırma sistemleri yanlış öngörüler nedeniyle yeterli kapasitede olmadığından havadan çok hafif olan $\mathrm{H}_{2}$ gazı üst kısımlarda birikmiş,

3) Patlama olayının gerçekleşmesi için gerekli olan tüm şartlar meydan gelmiş,

4) Sonuç olarak yaşanan patlama sonrası güvenlik sistemlerinin hasar görüp işlevini yitirmesi dolayısı ile çevreye radyasyon yayılmış ve sonuçları önlenemeyen ulusal ve uluslar arası güvenlik sorunları ile karşı karşıya kalınmıștır.

5) Bu çalışmada NGS'de meydana gelen Hidrojen gazı patlamasının nedeni niceliksel bir analiz modeli uygulanarak açıklanmıştır.

Elde edilen bu sonuçların ise zamana ve miktara bağlı olarak nükleer reaksiyonlar sonucu NGS'de oluşan enerjinin kontrol edilerek uzaklaştırılamaması durumunda hangi sürede ne boyutta bir kaza yaşanabileceğinin önceden tahmin edilebilmesi ve gerekli aktif ve pasif güvenlik önlemlerinin bu duruma göre tasarlanması için yaşanan bir olay üzerinden ulaşılmış önemli nicel ve somut verilerdir.

\section{KAYNAKLAR}

Cebe, M. (2014). Fizikokimya 1, Ekin Kitabevi Yayınları, Cilt II.

Gunter, P. (2004). Natural Disasters and Safety Risks at Nuclear Power Stations. NIRS (Nuclear Information and Resource Service). Washington, DC. USA.

Güler, T. (2006). Nükleer Enerji Üretim Sürecinde Kazalar, Nükleer atıklar ve Çevre Sorunları. Yayınlanmamış Yüksek Lisans Tezi. Ankara. Gazi Üniversitesi Sosyal Bilimler Enstitüsü Kamu Yönetimi.

Keski-Rahkonen, O., Mangs, J. (2002). Electrical ignition sources in nuclear power plants: Statistical, modeling and experimental studies. Nuclear Engineering and Design.

Özbay, E. ve Gençoğlu M. T. (2011). Küçük Hidroelektrik Santrallerde Yük-Frekans Kontrolü. Firat Üniverstesi Mühendislik Bilimleri Dergisi, 23 (2), 119-128. 
Nükleer Santrallerde Yangın Güvenliği Açısından Reaktör Soğutmanın Önemi ve Fukuşima Daiichi Kazası Modeli Üzerinden Kontrol Dıșı Gerçekleșen Fisyon Reaksiyonlarının Enerjisinin Hesaplanması Mühendis ve makine Dergisi, Cilt 53, Sayı 626, Technical report: Fukushima Accident Summary (Aug. 19, 2011) Ritsuo Yoshioka, Kenji Lino. (çeviri Yeliz Demir)

URL 1, http://kurumsalarsiv.taek.gov.tr/bitstream/1/101/2/30008.pdf (Son Erişim: 01.02.2019).

URL 2, https://www.taek.gov.tr/tr/2016-06-09-00-43-55/135-gunumuzde-nukleer-enerji-rapor/835bolum-05-nukleer-guvenlik.html (Son Erişim: 01.02.2019).

URL 3, https://www-pub.iaea.org/MTCD/Publications/PDF/INES_web.pdf (Son Erişim: 01.02.2019).

URL 4, https://pris.iaea.org/PRIS/WorldStatistics/UnderConstructionReactorsByCountry.aspx (Son Erişim: 01.02.2019)

URL 5, http://climatesceptics.org/ines-level/table Climate Skeptics. (2013). "Nuclear Power in Europe", (Son Erişim: 01.02.2019).

Vinod, G., Saraf, R. K., Ghosh, A. K., Kushwaha, H. S., \& Sharma, P. K. (2008). Insights from fire PSA for enhancing NPP safety. Nuclear Engineering and Design, 238(9), 2359-2368. 